\title{
Challenges and strategies proposed by genetic health professionals to assist with family communication
}

\author{
Alison L. Young $\mathbb{1}^{1,2} \cdot$ Phyllis N. Butow ${ }^{1} \cdot$ Katherine M. Tucker ${ }^{3,4} \cdot$ Claire E. Wakefield $^{2,5} \cdot$ Emma Healey $^{6} \cdot$ \\ Rachel Williams ${ }^{3,4}$
}

Received: 29 January 2019 / Revised: 24 May 2019 / Accepted: 31 May 2019 / Published online: 12 June 2019

(c) The Author(s), under exclusive licence to European Society of Human Genetics 2019

\begin{abstract}
Hereditary genetic conditions have implications for the whole family and therefore genetic health professionals (GHPs) interact with multiple family members, sometimes individually and sometimes in aggregate. Family communication is important to ensure dissemination of genetic information to potentially affected relatives and to facilitate supportive family interactions around genetic testing and risk management decisions. Yet, little is known about how GHPs perceive and manage these interactions. A total of 73 GHPs working across Australian cancer genetic clinics participated in semistructured focus groups or interviews to elucidate what aspects of family communication they found most challenging, the strategies they used, and whether current academic training provides sufficient guidance to address familial concerns. Patients' lack of understanding about the importance of communicating genetic information to at-risk relatives was the most common challenge reported. GHPs reported that the patients' concern for their families' emotional responses as well as wider family system challenges (e.g. estrangement) affected family communication. Common strategies during consultations included structuring appointments logistically to account for family dynamics and post-consultation use of family letters and follow-up appointments. GHPs generally felt equipped with the skills and training provided to address patient concerns, but also desired upskilling in techniques relating to systemic family issues and behavioural change. Reflective practice strategies were requested by geneticists and nurses to foster therapeutic skill usage. Additional family therapy training while on the job may be beneficial in order to meet current challenges faced in clinical practice and can be provided as further professional development.
\end{abstract}

Alison L. Young

ayou1666@uni.sydney.edu.au

1 The University of Sydney, Faculty of Science, School of Psychology, Centre for Medical Psychology \& Evidence-based Decision-making (CeMPED), Sydney, NSW, Australia

2 Behavioural Sciences Unit proudly supported by the Kids with Cancer Foundation, Kids Cancer Centre, Sydney Children's Hospital, Randwick, NSW, Australia

3 Prince of Wales Clinical School, Faculty of Medicine, University of New South Wales, Randwick, NSW, Australia

4 Prince of Wales Hereditary Cancer Centre, Prince of Wales Hospital, Randwick, NSW, Australia

5 School of Women's and Children's Health, University of New South Wales, Sydney, NSW, Australia

6 Illawarra Cancer Care Centre, Wollongong Hospital, Wollongong, NSW, Australia

\section{Introduction}

In the past few decades, the identification of pathogenic variants that increase the risk of certain health conditions has enabled patients to have genetic testing and, in some cases, mitigate their risk of disease substantially. A pathogenic variant that may increase the risk for disease has implications not only for the tested individual, but also the wider family. Such implications are expansive, and can impact lifestyle, risk management, and family planning decisions of both current and future generations. One example is a pathogenic variant of the $B R C A 1$ or $B R C A 2$ gene (hereafter $B R C A 1 / 2$ ), increasing the risk of breast, ovarian, and prostate cancer [1]. BRCA1/2 genes function to protect against cancer, but increase the chance of cancer when they cease to function properly [2].

Offspring are at $50 \%$ risk of inheriting a BRCA1/2 pathogenic variant from their affected parent [2]. It is 
therefore important for families to communicate about the family's genetic status, the pros and cons of genetic testing, testing results, and risk management options. Yet, such communication can be complex. Even patients without family dynamic difficulties may choose not to inform at-risk relatives of their genetic status for a variety of reasons [3]. Common reasons include concern for the emotional welfare of relatives, guilt, and a loss of contact due to geographical distance [4]. Pre-existing negative familial processes and relationship dynamics can also make such communication processes challenging. Both immediate and extended family members may not be informed about their risk due to conflicts, disagreements, and ongoing relational strain; a genetic test result can bring liabilities and 'old wounds' to the fore [4].

Clinical practice guidelines for genetic health professionals (GHPs), which were based on a UK/ Australian prospective study on the frequency of GHPs' concerns for non-disclosure among families with varying hereditary illnesses [5], and are in accordance with privacy laws, list common family dynamic problems encountered by GHPs. These include breakdown in relationships, perception that the relative is too unwell or busy, fear of confirming non-paternity or non-maternity, and cultural or religious factors [6]. Thus, GHPs are frequently confronted with the need to work with and support families to resolve challenges and communicate appropriately.

Upholding a patient's wishes, while also taking a family-centred approach, is reportedly one of the most challenging aspects of genetic consultations [7]. GHPs have been reported to use a variety of strategies to facilitate family communication. According to a survey of 626 international GHPs [8], family communication can be facilitated through the provision of genetic clinic contact details to patients (provided by 97\%), a summary letter to the patient (provided on average by $79 \%$ of GHPs), or a genetic clinic appointment for at-risk relatives (provided by $66 \%$ ). However, little is known about how GHPs interact with families during a consultation or their responses to family communication challenges. If GHPs are going to facilitate family communication, it is important to understand their current clinical and training practices.

Our study aims were therefore three-fold: [1] to identify the most common challenges faced by GHPs when addressing family communication with $B R C A 1 / 2$ families, [2] to explore GHPs' strategies for the management of challenges, and [3] to explore GHPs' current training and need for future training in navigating family communication processes.

\section{Method}

\section{Study participants and recruitment}

Cross-sectional focus groups and semi-structured interviews were conducted in 2017 with GHPs within public hospitals across all states of Australia. Eligible GHPs attending professional meetings and/or through email invite were contacted and a suitable time was arranged for a focus group/interview.

\section{Procedures and measures}

Participants completed a short questionnaire eliciting demographic and professional information, and nominated and ranked in descending order the top five common challenges experienced with family communication. Focus groups (maximum eight individuals) and interviews (if unable to attend focus group timeslots) were held in-person or via video-teleconferencing, facilitated by a trained qualitative researcher with expertise in family system theory (A.L.Y.), and audiotaped. Topics relating to challenges, strategies employed, and training received and needed on family communication, were explored. The appropriate ethics committees approved this study. All participants gave written or electronic consent to participate.

\section{Data analysis}

Demographic data were summarised using descriptive statistics. Two authors (A.L.Y. and R.W.) ranked and categorised GHPs' questionnaire responses about common challenges faced with family communication. An overall ranked score for each challenge category was calculated (overall mean rank of each category multiplied by the frequency with which it was reported). Focus groups and interviews were transcribed verbatim and underwent thematic analysis [9]. Consideration was given to whether individuals participating in one method (i.e. focus groups) differed in relation to the experiences discussed in the other method (i.e. interviews). Emphasis was placed on the themes mentioned by the majority of participants and data that raised novel lines of inquiry, reflecting unique subthemes (e.g. rurality and specialists). Three authors (A.L.Y., P.N.B., and R.W.) analysed the first six transcripts by rereading each transcript, generating codes, and developing overall themes, which were then organised into a thematic 'map'. Differences in coding were resolved by consensual discussion. Subsequent transcripts were analysed according to the 'map', adding further themes through an iterative process, resulting in defining a final set of themes. Focus group or individual interview identification (e.g. FG4 or II4) is provided below. 


\section{Results}

\section{Sample characteristics}

A total of 16 focus groups and 12 in-depth individual interviews were conducted with GHPs. Seventy-three GHPs participated (91 invited), with the majority working as a genetic counsellor (80\%). Most were Caucasian (86\%), female (92\%), and married (62\%) (Table 1).

\section{Common GHP perceptions of the family communication challenges}

Participants identified and ranked a range of family communication challenges (Table 2). Combined with the qualitative data, four broad systemic challenges to family communication were identified, which are described below.

\section{Relationship dysfunction}

Family relationship breakdown, including estrangement and/or strained relationships, were ranked by GHPs as one of the most common systemic challenges detracting from family communication. Genetic testing can lead to relationship dysfunction or accentuate pre-existing problematic relational patterns. GHPs noted that patients could use genetic information as a 'weapon' against their relatives (FG3). For example, there are families "where there's like a family dispute and they're actively not going to tell that

Table 1 Sample characteristics

\begin{tabular}{lc}
\hline Genetic health professionals $(N=73)$ & No. $(\%)$ \\
\hline Mean age in years at interview (range) & $39.81(23-64)$ \\
Cultural background ${ }^{\mathrm{a}}$ & $63(86.30)$ \\
Caucasian & $9(12.33)$ \\
Other & \\
Marital status ${ }^{\mathrm{a}}$ & $19(26.03)$ \\
Single & $45(61.64)$ \\
Married & $7(9.59)$ \\
$\begin{array}{l}\text { De facto/partnered/engaged } \\
\text { Other }\end{array}$ & $1(1.37)$ \\
$\begin{array}{l}\text { Employment } \\
\text { Genetic counsellor }\end{array}$ & $59(80.82)$ \\
$\begin{array}{l}\text { Other (e.g. geneticists, nurses, oncologists, } \\
\text { psychologists/psychiatrists) }\end{array}$ & $13(17.81)$ \\
$\begin{array}{l}\text { Average years practicing (range) } \\
\text { Average hours each week in direct contact with } \\
\text { patients at-high risk of breast/ovarian cancer } \\
\text { (range) }\end{array}$ & $7.53(0.05-27.50)$ \\
\hline
\end{tabular}

${ }^{a}$ Missing demographic data $(n=1)$

${ }^{\mathrm{b}}$ Missing demographic data $(n=3)$ sister or whatever because they don't speak and they don't care what happens to them" (FG7). It was considered rare for a mother not to pass on information to her children, but for carrier fathers who had limited contact with their children due to a divorce or separation, communication was considered "kind of opening another issue that may be seen as a negative towards them" (FG12). Blame and anger are ensuing emotions that patients had discussed with GHPs. For example, a genetic counsellor said, "I have had one male, who came through and he was positive and when I gave the result he was devastated and said, 'Oh, my wife and my daughter will blame me for this straight out. It's just the way it is in this family. It's just another thing they will blame me for'... It's the catalyst [the relatives] need to be angrier because they already were, but now they've got this..." (FG20).

\section{Loss of contact or death}

Another issue was alienation or loss of contact between relatives, causing patients to view communication as "a massive burden" (II11), particularly when delivering "bad news'. Individuals "just don't want to have a difficult conversation with someone that they don't have a lot of contact with, [or] may not have seen since they were a child" (FG12). Patients were unsure how to broach the topic, what to say, and when and to whom the information was of relevance. Identifying relatives for whom genetic information is of relevance was a challenge for GHPs when individuals had lost contact with the rest of the family or been adopted.

For some families, a loss of contact has occurred naturally, and trying to make contact is just "completely outside the realms of knowing where they live" (II13). For others, geographical distance can be a perceived barrier, "they will say, 'Oh actually my relatives are overseas'-it's almost as though they're not part of the family anymore they're so distant from me" (FG4). A clinical process issue can also be encountered by genetic services with overseas relatives, in that after dissemination of information is achieved, "the next blockage is often [directing] someone to a service ... [but a relatives'] ability, even if they want to act on that, is sometimes unclear" (FG4), especially in countries where testing is unavailable, or not widely performed.

GHPs reported that the death of a relative (and subsequent remarriage, change of surnames, lost contact details) can have far-reaching consequences relating to the loss of "usual networks" (FG), and be an added burden on families that are yet to be informed of a pathogenic variant that may increase the risk for disease. A common case reported was when a female partner has died and the husband "doesn't talk to her side of the family anymore or ... one of the big complications is actually various people have 
Table 2 Genetic health professionals perceived challenges relating to family communication about genetic cancer risk ranked in order of importance

\begin{tabular}{|c|c|c|c|c|c|}
\hline & & Freq & Mean & SD & Overall Ranking \\
\hline 1 & $\begin{array}{l}\text { Lack of understanding of importance to inform others, lack understanding of significance, } \\
\text { misinformation of cancer risk, misinformation of inheritance }\end{array}$ & 39 & 1.58 & 1.95 & 61.75 \\
\hline 2 & Emotional responses_-guilt, anxiety, fear, grief, blame, shame & 33 & 1.14 & 1.61 & 37.77 \\
\hline 3 & Family relationship breakdown—estrangement, strained & 34 & 1.01 & 1.35 & 34.48 \\
\hline 4 & $\begin{array}{l}\text { Relatives' perceived reactions-concerned that relatives will be 'emotionally burdened', lack the } \\
\text { understanding, uninterested or blame the proband }\end{array}$ & 29 & 1.00 & 1.49 & 29.00 \\
\hline 5 & Loss of contact including geographic distance and death & 25 & 0.82 & 1.36 & 20.45 \\
\hline 6 & Privacy, insurance concerns, confidentiality, preserving autonomy, and non-consent & 16 & 0.92 & 1.77 & 14.70 \\
\hline 7 & Pre-existing lack of communication (generally, medical-specific) or relationship difficulties & 21 & 0.68 & 1.33 & 14.19 \\
\hline 8 & $\begin{array}{l}\text { Lack of perceived closeness to relatives } \& \text { initiating contact around "bad news", particularly with } \\
\text { extended family or those they have not spoken to before }\end{array}$ & 17 & 0.71 & 1.39 & 12.01 \\
\hline 9 & Unsure how to broach the topic, what to say, when and to whom & 17 & 0.71 & 1.50 & 11.99 \\
\hline 10 & $\begin{array}{l}\text { Deciding the timing of sharing genetic risk during stressful life events e.g. cancer diagnosis, treatment, } \\
\text { other concurrent stressors, anniversaries of loss }\end{array}$ & 16 & 0.72 & 1.48 & 11.58 \\
\hline 11 & Family role as a "protector" and feeling responsible for disclosure & 13 & 0.59 & 1.36 & 7.61 \\
\hline 12 & Ensuring correct information is communicated & 12 & 0.61 & 1.46 & 7.36 \\
\hline 13 & Non-disclosure-active blocking, passive non-disclosure, procrastination & 10 & 0.45 & 1.23 & 4.53 \\
\hline 14 & $\begin{array}{l}\text { Identifying to which relatives the information is of relevance, e.g. inability to establish from which } \\
\text { side a mutation arose, adopted }\end{array}$ & 9 & 0.48 & 1.28 & 4.32 \\
\hline 15 & Reduced sense of urgency for males and males communicating less & 5 & 0.30 & 1.04 & 1.49 \\
\hline 16 & Generational conflict of values & 4 & 0.19 & 0.73 & 0.75 \\
\hline 17 & $\begin{array}{l}\text { Resource or service access difficulties_relatives limited healthcare access, follow-up, tailoring family } \\
\text { letters }\end{array}$ & 3 & 0.21 & 0.95 & 0.64 \\
\hline 18 & Inadvertent discovery of status through children, VUS reclassification, ineligible testing & 3 & 0.13 & 0.66 & 0.40 \\
\hline 19 & Not feeling responsible for disclosure & 3 & 0.12 & 0.59 & 0.36 \\
\hline 20 & Collusion with GHPs-wanting children tested without their knowledge & 1 & 0.05 & 0.37 & 0.05 \\
\hline
\end{tabular}

died and they've lost communication-they've lost those sort of usual networks that they would have if everyone was still healthy, well and living. So [patients are] just like 'I know these people exist but I can't get in contact with them because I don't know where they live..." (FG1). A specific example provided was a case in which a mother in her $40 \mathrm{~s}$ died, but wanted her daughter to have testing before she died. Her daughter complied and tested positive. After her mother's death, the daughter was left with the responsibility to inform her siblings and extended family overseas which was "a huge burden for her to have on top of everything else" (FG4).

\section{Pre-existing communication patterns}

GHPs also perceived that pre-existing communication problems in the family were difficult to navigate. As one genetic counsellor said, "I think families bring it with them. I think we can obviously help or hinder a little bit in what we say and what we express is important to communicate, but if a family has poor communication there's not heaps we can do to help. I want to say we can but we really can't" (FG1). On the flip side, GHPs generally believed that when there were open lines of communication in the family, which was most often the case, a discussion about disseminating information to relatives occurred relatively easily and "spreads like wildfire" (FG1). Nevertheless, GHPs reported that some families, although considered open communicators, do not speak about medical or health information in the family: "it's probably with people with historical, cultural issues about not discussing health within families or illness, in particular...cancer" (II16) or are "private [about] their health" (FG8).

\section{Cross-generational issues}

Cross-generational issues such as power differentials, differences in values, and one generation trying to protect the next were also discussed by GHPs. Older patients/probands were considered 'gatekeepers' and could withhold or distort information. GHPs reported that parents (typically mothers) 
expected that their children act in accordance with their values (e.g. not have surgery), and sons were typically "dragged" to consultations (FG3) by their mothers, often unmotivated, unready or indifferent about making decisions about their genetic risk. Early career GHPs found it particularly difficult to navigate through the disclosure of results when patients wanted to enforce their values on others (FG20).

Explaining to patients that it would be more beneficial to test grandparents or older adults before testing grandchildren was also a challenge. For some this was not possible if their older relatives had actively chosen not to have testing. It was particularly difficult to convince older relatives to be tested if they considered the information of little relevance to themselves, "they don't recognise our process was we really wanted to test one person instead of testing [their] five or seven children" (II17). ${ }^{1}$

\section{GHPs' strategies for working with family communication challenges}

GHPs identified a number of strategies for working with families, discussed below.

\section{Assessing family communication and family dynamics early}

GHPs noted the importance of assessing family communication and dynamics during pre-counselling phone assessments at the first appointment, to clarify what "extra things that [the GHP was] going to need" to support that family (FG3) both initially and in dealing with ongoing difficulties if the proband tests positive. Some GHPs noted that explicitly querying whether there may be a problem (e.g. tension between family members or that one person appears to be protecting another) could be helpful at this stage, "they might not actually have much insight in to the way they see themselves and the way they see their [relative]" (FG3).

GHPs also noted the importance of cueing patients to begin thinking early about potential communication challenges if they tested positive so that they can be prepared: "they often haven't thought about - oh, that if I'm not negative and then have to talk about it with people, it's when they come back being positive it's something that they haven't even considered having to deal with" (FG24). Identifying challenges can occur at set times during a consultation such as completing a family pedigree (II11) or "on a case by case basis ... [when it] comes up then we try and troubleshoot" (FG12).

\footnotetext{
${ }^{1}$ It is standard practice to test the older generation first to identify whether they are a carrier of a $B R C A 1 / 2$ pathogenic variant. If they are not a carrier, testing of their offspring is not required
}

Facilitating disclosure with estranged families

GHPs used various strategies to assist patients who are estranged or who have lost contact with family members. Some GHPs recommended identifying a key person in the family to serve as a 'proxy' disseminator of information, especially when the patient does not want to answer questions. Some GHPs provide a family letter to the patient to give to their relatives, which was reported by some to be very successful in addressing family dynamics (FG22), since "that kind of externalises it from them ... [especially when there's an] underlying issue that existed before the genetics" (FG21). Other GHPs reported that a family letter did not suffice in all situations: "most of them didn't understand what the letter was and they had no recollection of receiving it... [or] they have read it and didn't understand it. Some of them read it and took it to the GP who told them not to worry about it" (II11). Checking with patients at follow-up whether they had communicated with their relatives was recommended by GHPs, particularly those working in rural communities where genetic services are limited and with the older generation, many of whom are unaware of the implications of genetics for their health.

\section{Ensuring autonomy and that everyone is heard}

GHPs felt that respecting personal autonomy was important, especially if differences in opinion amongst family members exist. For example, GHPs sometimes requested that a young person suspected to be complying with testing for the sake of their parent, be encouraged to make their own appointment, or have a pre-counselling phone discussion. GHPs would sometimes suggest that each family member attend a separate appointment prior to a joint consultation. They also considered setting up the room so that the chairs were in a circle, instead of some members sitting behind each other. GHPs reported using these practices in situations involving parent-child conflict of values and sibling-sibling differences in opinion towards genetic testing or risk-reducing surgery.

\section{Referring to psychosocial GHPs}

Being aware that a situation is beyond the expertise or skillset of a given profession and making appropriate referrals to other GHPs or services were considered important skills and a benefit of a multidisciplinary team approach. As one GHP said, "often we do need to engage outside help because that family has another problem of which the genetics is just a small part" (FG3). Referral to psychologists, through referral to a primary care provider/ general practitioner (GP), was considered vital. Referrals were made when there were deep-seated issues with family 
dynamics, pre-existing mental health issues and blame or anger towards relatives. For example, one GHP said, "recognising what is in front of you goes beyond yourself is important to referring on and these people need ongoing psychological support more than we can offer really" (FG23).

\section{Current and future GHP training}

There was variability in the amount of time participating GHPs had worked within the field (i.e. 6 months to 23 years) and therefore the training they reported having received was different. Genetic counsellors who had qualified in the last few years reported that their Master's degree provided them with theoretical knowledge of family systems and experience role playing or learning about communication problems in different case studies. Those who were considered senior genetic counsellors were more likely to report that their degree did not include family systems training at the same level as currently provided. Regardless of the training received, GHPs reported that they learnt strategies and problem-solving skills while on the job and by discussing difficult cases with their colleagues. They also debriefed with colleagues and sought mentorship. After a difficult consultation with a family, the "first thing you do is you go and talk to someone ... your supervisor [to] workshop how you could have done that differently so there's a real onus on learning from your experience and developing as a counsellor" (FG4).

Genetic counsellors desired engagement in reflective practice by considering alternative methods of handling the same situation. Early career genetic counsellors and geneticists also wanted ongoing additional assistance to improve their skills in this arena. Many GHPs said they needed general strategies to probe patients about family communication, "it might not be like an intervention as such but maybe some tools to be informing the types of questions you might ask to work out how that family works so that you can work within that system" (FG23). Training in techniques to increase behavioural change was particularly desired when working with families with active riskmanagement options available (e.g. BRCA1/2), "because you need people to know what stuff is within their power and control" (FG24).

GHPs commonly felt that they did not have enough time to delve into family dynamics and some were also perplexed about when and to what extent such discussions were most appropriate. For example, one GHP said, "We often know where there is a problem; we can recognise there is an issue or a dynamic but then don't know what to do with it ... something's going on there but then you don't know whether that's a good thing to unpack" (FG21).
The optimal timing of training in family communication was debated since some GHPs believed that getting taught on-the-job through workshops was much more beneficial than during a degree, because, "it's like any skill if you don't apply it, it gets rusty really quickly" (FG21). However, GHPs have diverse professional standards, requirements, and opportunities to engage in ongoing professional development; as one genetic counsellor said, "It is difficult to balance new training within current demands" (FG23). While both geneticists and genetic counsellors reported a lack of training in how to facilitate family communication, genetic counsellors were more likely than geneticists to have received some training; as one genetic counsellor said, "I think that's probably a difference between medical training and counsellor's training that probably helps us in that regard" (FG4). Medically trained GHPs reported that having reflective practice and debriefing as a common practice within their profession could assist them in learning strategies from their peers to handle cases where family dynamics are an issue.

\section{Discussion}

This is one of the first studies to describe the most common challenges faced by GHPs when addressing family communication with BRCA1/2 families. When asked to name and rank the challenges they experienced when dealing with families, six out of the first ten challenges were systemic familial issues. Previous research reported that prior relationship difficulties (e.g. estrangement, perceived distance or strained relationships) can impede communication with parents [10], and with extended family members [3], and a genetic test result can heighten these difficulties [4]. Other studies have noted that the potential impact of genetic disclosure on family wellbeing and relationships is one of the most common concerns raised by probands [11].

The GHPs in this study noted a number of useful strategies used to overcome family estrangement, dysfunction, and conflict. Strategies include: assessing, acknowledging, and preparing for difficulties early in the process, identifying a neutral family member who might communicate optimally, providing a family letter to externalise communication, ensuring that all family members have autonomy and are heard through individual consultations, respectful communication and inclusive consultation set-up, and referral to psychosocial GHPs if required. These strategies can supplement those suggested elsewhere [12]. Direct contact with at-risk relatives by letter from a genetic clinic is suggested in the UK [13] and France [14]. This practice is occurring in only one state of Australia (i.e. South Australia) [15] due to differences in state legislation. Internationally there is ongoing discussion about the clinical 
and legislative implications of direct contact practices [16], with additional considerations about the return of results in the paediatric setting [17]. Despite the method of contact, family therapy techniques will be of increasing benefit for GHPs encountering family dynamic challenges that hinder at-risk relatives from attending a genetic clinic.

GHPs may increase their skills to assist with disclosure by undertaking family therapy training. In accordance with the 2017 guidelines governing accreditation of Master of Genetic Counselling programs within Australia [18], students need to show competency in evaluating their patients' psychosocial history by assessing family dynamics and recognising the role of relationships in families. Despite learning these skills, GHPs wanted further training when they were most likely to use it: on-the-job. Workshops and skills training are considered beneficial for further professional development and can be extended to assist nongenetic health professionals.

Upskilling a whole genetic clinic can be resource intensive, but upskilling a member of each clinic in family therapy techniques is plausible. Psychological therapeutic skills including behavioural modification skills, motivational interviewing, and cognitive-behavioural techniques may be beneficial for genetic counsellors to utilise or at the very least, understand so that they can identify families needing further support. Nevertheless, due to time constraints genetic counsellors have a limit on how much they can address family dynamic issues and therefore referral to specialists and other allied healthcare providers is important. Psychologists and psychiatrists have the luxury of extended consultations and resources to explore family issues and are considered helpful when barriers to communication exist [19].

Family-based interventions may also help in this context [20]. Few genetic interventions have been formally evaluated to improve family communication; there has been a recent call for interventions to explore family dynamics processes and target the reasons for lack of communication [21] including the use of a guiding framework to create a 'toolbox' of interventions at a GHPs disposal [22]. RCTs using telephone interventions addressing family communication show inconclusive results. A non-directive telephone intervention at three time-points resulted in relatives making significantly more contact with genetic services compared to controls, but with no overall difference in communication [23]. No difference in communication was also observed in a telephone intervention RCT [24], but since familial communication was high at baseline within the intervention group, efficacy cannot be ascertained.

A more comprehensive intervention to target family communication is multi-family discussion groups (MFDGs), which allow families to learn, support, and reduce stigma in a group setting facilitated by GHPs [25].
MFDGs have been developed to assist patients in mental health, chronic health, and hereditary conditions [25]. When applied to the genomic medicine context, psychologists have generally been employed to facilitate family therapy interventions [26]. However, a group of UK researchers and clinicians have attempted to train genetic counsellors to implement a psycho-educational intervention using MFDGs to improve parent-child conversations [27]. Genetic counsellors were taught family therapy concepts and techniques, focusing on the families' relational and emotional wellbeing, including their overall confidence in coping with genetic information. An intervention pilot [27] highlighted the potential utility of training genetic counselling staff onthe-job and providing them with family therapy skills, to use particularly with families, which are burdened by the genetic information provided. Family care nurses are also considered to be a viable specialty in addressing the longterm needs of families, by providing follow-up care throughout the lifespan, ensuring ongoing assessment of dissemination by tracking each member of the family [20]. Training genetic clinic staff in family therapy will enhance the current skills set of the multidisciplinary team.

\section{Clinical implications}

We would argue that all GHPs would be eligible for and benefit from training in therapeutic skills that address familial communication processes. Given that family therapy appears to be a small component of the accreditation requirements for genetic counselling Master's degrees [18], further training is needed to enhance GHPs' identification of families with limited communication. Family therapy techniques would be most effective during the initial consultation to identify family dynamic issues that could be a problem, and at follow-up to identify and address ongoing family communication barriers. This may entail changes to the current model of practice to allow for more contact with genetic counsellors post-consultation during follow-up. GHPs (e.g. geneticists, oncologists, and nurses), can benefit from including reflective practices and debriefing, potentially with the multidisciplinary team, to enhance learning with difficult cases. While many training courses for GHPs are already heavily loaded with content, providers may benefit from learning more about identifying families with poor communication. Such training could assist GHPs to identify when it would be beneficial to refer patients and families to other specialists (e.g. psychologists and psychiatrists). Such training in understanding family dynamics and dissemination issues could also benefit non-genetic-related clinicians who provide care for people with hereditary cancer conditions [28]. While genetic counsellors may be the ideal GHPs to address family communication issues, it will be 
increasingly common as genetics moves into mainstream medicine, for doctors to gain consent and deliver results to patients, sometimes without any referral to a genetic clinic. Therefore, they will also need a basic understanding of family dynamics and skills to encourage communication. As this rarely occurs in tertiary or advanced training, additional focused training will need to be provided. GHPs may find that a check-list of questions to probe for potential family relational and dynamic barriers would be beneficial, much like the 'question prompt list' used with cancer patients [29] or the 'key messages' for $B R C A 1 / 2$ patients suggested by Jacobs et al. [30]. Prompting short questions and statements to encourage communication can be of particular assistance for medical oncologists and general practitioners to address family communication efficiently. Additional training will also be of benefit for GHPs working with emerging young adults [20, 31], at-risk males [4, 31] and patients from culturally and linguistically diverse backgrounds [31], and to those giving germline results from multigene panels and whole genome sequencing testing [32].

\section{Limitations}

A possible limitation of the current study is that GHPs were asked to focus on family communication challenges that exist with $B R C A 1 / 2$ patients; different challenges may have been discussed had other genetic health conditions been included. However, similar difficulties in relation to family communication are likely to be encountered across conditions (e.g. Huntington's disease) [21].

The majority of the sample were genetic counsellors (80\%) and although GHPs from other specialties (20\%) provided different and varying opinions within focus groups, the concerns of genetic counsellors were predominant when it came to discussions about family communication challenges. Further research is required, with larger samples of geneticists, surgeons, nurses, and psychologists, in order to elucidate whether their concerns and need for training differs from those of genetic counsellors. Moreover, information on non-responders was not available. Nevertheless, the study reflects the current genetic workforce that presides within Australian genetic clinics and is comparable to clinics worldwide using a similar clinical structure.

\section{Conclusion}

This study demonstrated that systemic family dynamic concerns, such as conflict, estrangement, and loss of contact, are challenging in genetic settings. GHPs are generally equipped to address educational and medical cancer-related concerns; however, upskilling geneticists, genetic counsellors, and nurses in techniques relating to systemic familyrelated issues, behavioural change, and reflective practice strategies can have promising effects in improving the dissemination and uptake of genetic testing.

Acknowledgements ALY is supported by the School of Psychology Margaret Stewart Fund Scholarship. CEW is supported by a Career Development Fellowship from the National Health and Medical Research Council of Australia (APP1143767). The Behavioural Sciences Unit at the Kids Cancer Centre is proudly supported by the Kids with Cancer Foundation.

Authors contributions ALY made a substantial contribution to the study design, acquisition of data, analysis, interpretation, and revisions for important intellectual content. PNB contributed to the conception, acquisition of data, analysis interpretation and drafting the work for important intellectual content. KMT contributed to the study design, acquisition of data, analysis interpretation and drafting the work for important intellectual content. CEW contributed to the acquisition of data, analysis, interpretation, and revisions for important intellectual content. EH contributed to the acquisition of data, analysis, interpretation, and revisions for important intellectual content. RW contributed to the study design, acquisition of data, analysis interpretation and drafting the work for important intellectual content. The corresponding author has had full access to the data in the study and final responsibility for the decision to submit for publication.

\section{Compliance with ethical standards}

Conflict of interest KMT has been on the advisory board, chaired a meeting and given talks for AstraZeneca Pharmaceutical. ALY, PNB, $\mathrm{CEW}, \mathrm{EH}$, and RW declare that they have no conflict of interest.

Ethics approval The project was approved by the University of Sydney Human Research Ethics Committee (HREC 2017/011), which covered the participating hospitals.

Informed consent All procedures followed were in accordance with the University of Sydney Human Research Ethics Committee) and with the Helsinki Declaration of 1975, as revised in 2000 (5). Signed or electronic consent was obtained from all participants. Informed consent was obtained from all participants for being included in the study.

Publisher's note: Springer Nature remains neutral with regard to jurisdictional claims in published maps and institutional affiliations.

\section{References}

1. Daly MB, Pilarski R, Berry M, Buys SS, Friedman S, Garber JE, et al. Genetic/familial high-risk assessment: Breast and ovarian, version 2.2019. J Natl Compr Canc Netw. 2018:1-81.

2. Petrucelli N, Daly MB, Feldman GL. Hereditary breast and ovarian cancer due to mutations in BRCA1 and BRCA2. Genet Med. 2010;12:245-59.

3. Lieberman S, Lahad A, Tomer A, Koka S, BenUziyahu M, Raz A, et al. Familial communication and cascade testing among relatives of BRCA population screening participants. Genet Med. 2018; 20:1446-54. 
4. Dancyger C, Wiseman M, Jacobs C, Smith J, Wallace M, Michie S. Communicating BRCA1/2 genetic test results within the family: a qualitative analysis. Psychol Health. 2011;26:1018-35.

5. Clarke A, Richards M, Kerzin-Storrar L, Halliday J, Young MA, Simpson SA, et al. Genetic professionals' reports of nondisclosure of genetic risk information within families. Eur J Hum Genet. 2005;13:556-62.

6. National Health and Medical Research Council. Use and disclosure of genetic information to a patient's genetic relatives under section 95AA of the Privacy Act 1988 (Cth). Guidelines for health practitioners in the private sector. Canberra: National Health and Medical Research Council; 2014 www.nhmrc.gov.au/guidelines/ publications/g8.

7. Forbes Shepherd R, Browne TK, Warwick L. A relational approach to genetic counseling for hereditary breast and ovarian cancer. J Genet Couns. 2017;26:283-99.

8. Forrest LE, Delatycki MB, Curnow L, Skene L, Aitken M. Genetic health professionals and the communication of genetic information in families: practice during and after a genetic consultation. Am J Med Genet A. 2010;152A:1458-66.

9. Braun V, Clarke V. Using thematic analysis in psychology. Qual Res Psychol. 2006;3:77-101.

10. Peters JA, Kenen R, Hoskins LM, Koehly LM, Graubard B, Loud JT, et al. Unpacking the blockers: understanding perceptions and social constraints of health communication in hereditary breast ovarian cancer (HBOC) susceptibility families. J Genet Couns. 2011;20:450-64.

11. Rowland E, Plumridge G, Considine A-M, Metcalfe A. Preparing young people for future decision-making about cancer risk in families affected or at risk from hereditary breast cancer: aqualitative interview study. Eur J Oncol Nurs. 2016;25:9-15.

12. Dheensa S, Fenwick A, Lucassen A. Approaching confidentiality at a familial level in genomic medicine: a focus group study with healthcare professionals. BMJ Open. 2017;7:e012443.

13. Dheensa S, Lucassen A, Fenwick A. Limitations and pitfalls of using family letters to communicate genetic risk: a qualitative study with patients and healthcare professionals. J Genet Couns. 2018;27:689-701.

14. d'Audiffret Van Haecke D, de Montgolfier S. Genetic diseases and information to relatives: practical and ethical issues for professionals after introduction of a legal framework in France. Eur J Hum Genet. 2018;26:786-95.

15. Suthers GK, Armstrong J, McCormack J, Trott D. Letting the family know: balancing ethics and effectiveness when notifying relatives about genetic testing for a familial disorder. J Med Genet. 2006;43:665-70.

16. Dheensa S, Fenwick A, Shkedi-Rafid S, Crawford G, Lucassen A. Health-care professionals' responsibility to patients' relatives in genetic medicine: a systematic review and synthesis of empirical research. Genet Med. 2016;18:290-301.

17. Zawati MnH, Parry D, Knoppers BM. The best interests of the child and the return of results in genetic research: international comparative perspectives. BMC Med Ethics. 2014;15:72.
18. Human Genetics Society of Australasia. Guidelines for accreditation of genetic counselling programs (Document No: 2010GL02). Australia: HGSA; 2017.

19. Derbez B, de Pauw A, Stoppa-Lyonnet D, de Montgolfier S. Supporting disclosure of genetic information to family members: Professional practice and timelines in cancer genetics. Fam Cancer. 2017;16:447-57.

20. Metcalfe A. Sharing genetic risk information: Implications for family nurses across the life span. J Fam Nurs. 2018;24:86-105.

21. Mendes Á, Paneque M, Sousa L, Clarke A, Sequeiros J. How communication of genetic information within the family is addressed in genetic counselling: a systematic review of research evidence. Eur J Hum Genet. 2016;24:315.

22. Wiens M, Wilson B, Honeywell C, Etchegary H. A family genetic risk communication framework: guiding tool development in genetics health services. J Community Genet. 2013;4:233-42.

23. Hodgson J, Metcalfe S, Gaff C, Donath S, Delatycki MB, Winship I, et al. Outcomes of a randomised controlled trial of a complex genetic counselling intervention to improve family communication. Eur J Hum Genet. 2016;24:356-60.

24. Eijzenga W, de Geus E, Aalfs CM, Menko FH, Sijmons RH, de Haes HCJM, et al. How to support cancer genetics counselees in informing at-risk relatives? Lessons from a randomized controlled trial. Patient Educ Couns. 2018;101:1611-9.

25. Asen E, Scholz M. Multi-family therapy: concepts and techniques. New York: Routledge; 2010.

26. Chiquelho R, Neves S, Mendes Á, Relvas AP, Sousa L. proFamilies: a psycho-educational multi-family group intervention for cancer patients and their families. Eur J Cancer Care. 2011;20:337-44.

27. Eisler I, Flinter F, Grey J, Hutchison S, Jackson C, Longworth L, et al. Training genetic counsellors to deliver an innovative therapeutic intervention: their views and experience of facilitating multi-family discussion groups. J Genet Couns. 2017;26:199-214.

28. Hamilton JG, Abdiwahab E, Edwards HM, Fang M-L, Jdayani A, Breslau ES. Primary care providers' cancer genetic testing-related knowledge, attitudes, and communication behaviors: a systematic review and research agenda. J Gen Intern Med. 2017;32:315-24.

29. Clayton JM, Butow PN, Tattersall MHN, Devine RJ, Simpson JM, Aggarwal G, et al. Randomized controlled trial of a prompt list to help advanced cancer patients and their caregivers to ask questions about prognosis and end-of-life care. J Clin Oncol. 2007;25:715-23.

30. Jacobs C, Pichert G, Harris J, Tucker K, Michie S. Key messages for communicating information about BRCA1 and BRCA2 to women with breast or ovarian cancer: consensus across health professionals and service users. Psycho-Oncology. 2017;26:1818-24.

31. Young AL, Butow PN, Rhodes P, Tucker KM, Williams R, Healey E, et al. Talking across generations: Family communication about BRCA1 and BRCA2 genetic cancer risk. J Genet Counsel. 2019;28:516-32.

32. Knoppers BM, MnH Zawati, Sénécal K. Return of genetic testing results in the era of whole-genome sequencing. Nat Rev Genet. 2015; $16: 553$. 